Original Article

\title{
Resetting the late timing of 'night owls' has a positive impact on mental health and performance
}

\author{
Elise R. Facer-Childs a, b, d, *, Benita Middleton ${ }^{c}$, Debra J. Skene ${ }^{c}$, Andrew P. Bagshaw ${ }^{\text {b, d }}$ \\ a School of Biosciences, University of Birmingham, Birmingham, B15 2TT, UK \\ ${ }^{\mathrm{b}}$ Centre for Human Brain Health, University of Birmingham, Birmingham, B15 2TT, UK \\ c Faculty of Health \& Medical Sciences, University of Surrey, Guildford, GU2 7XH, UK \\ d School of Psychology, University of Birmingham, Birmingham, B15 2TT, UK
}

\section{A R T I C L E I N F O}

\section{Article history:}

Received 8 January 2019

Received in revised form 1 May 2019

Accepted 3 May 2019

Available online xxx

\section{Keywords:}

chronotype

circadian phase markers

non-pharmacological interventions

depression

stress

performance

\begin{abstract}
A B S T R A C T
Background: There is conflict between living according to our endogenous biological rhythms and our external environment, with disruptions resulting in negative consequences to health and performance. This is often documented in shift work and jet lag, but 'societal norms' (eg, typical working hours) can create profound issues for 'night owls', people whose internal biological timing predisposes them to follow an unusually late sleep-wake cycle. Night owls have also been associated with health issues, mood disturbances, poorer performance and increased mortality rates.

Methods: This study used a randomized control trial design aimed to shift the late timing of night owls to an earlier time (phase advance), using non-pharmacological, practical interventions in a real-world setting. These interventions targeted light exposure (through earlier wake up/sleep times), fixed meals times, caffeine intake and exercise.

Results: Overall, participants demonstrated a significant advance of $\sim 2 \mathrm{~h}$ in sleep/wake timings as measured by actigraphy and circadian phase markers (dim light melatonin onset and peak time of the cortisol awakening response), whilst having no adverse effect on sleep duration. Notably, the phase advance was accompanied by significant improvements to self-reported depression and stress, as well as improved cognitive (reaction time) and physical (grip strength) performance measures during the typical 'suboptimal' morning hours.

Conclusions: Our findings propose a novel strategy for shifting clock timing towards a pattern that is more aligned to societal demands that could significantly improve elements of performance, mental health and sleep timing in the real world.
\end{abstract}

๑ㅇ 2019 Elsevier B.V. All rights reserved.

\section{Introduction}

Often, there is little regard for the impact of sleep and circadian disruptions in society's attitude towards the organisation of our typical working day. Disturbances to the sleep/wake system that impair daily functioning leading to reduced health are prevalent, with around two thirds of the UK's adult population (67\%) reporting some sort of sleep issue [1,2]. It is well documented that restricted sleep and disrupted circadian rhythmicity result in changes to many physiological processes such as endocrine regulation [3] and

* Corresponding author. Turner Institute for Brain and Mental Health, School of Psychological Sciences, Monash University, 1/270 Ferntree Gully Road, Notting Hill, VIC, 3168, Australia.

E-mail address: Elise.Facer-Childs@monash.edu (E.R. Facer-Childs). core body temperature (CBT) [4], as well as being linked with a variety of health issues, including mood disturbances [5], increased morbidity and mortality rates [6], and declines in cognitive and physical performance [7]. Disruption to circadian and sleep/wake processing represents a substantial economic burden on society, primarily through loss of productivity, absenteeism and poor performance [8], and increases the risk of occupational accidents [9]. A major factor influencing these outcomes is a lack of appreciation for individual differences in vulnerability to sleep disruption and circadian misalignment, and a lack of awareness of the extent to which an individual's circadian timing may not align with the normal 09:00 h-17:00 h working day.

Individual differences in biological rhythms are influenced by physiological [10,11], genetic [12] and behavioural [13] factors. These differences allow the categorisation of individuals according 
to their circadian timing, with particularly early and late timings often referred to as 'larks' and 'night owls' (termed Early and Late circadian phenotypes, ECP/LCP, in this study). At their most extreme these differences can result in clinical diagnoses of the circadian rhythm sleep-wake disorders (CRSWDs), Advanced Sleep-Wake Phase Disorder (ASWPD) and Delayed Sleep-Wake Phase Disorder (DSWPD), which are more prevalent in older and younger subjects, respectively. The extent to which these clinical disorders overlap in terms of mechanisms with extreme circadian phenotypes in the healthy population remains unknown.

DSWPD is often associated with mood disorders such as depression [14], and this group of individuals also tend to be restricted by social factors such as work/school routines which shorten sleep resulting in an accumulation of 'sleep debt'. This causes excessive sleepiness during the day and impairment of cognitive functioning [15]. While clinical assessment is needed to diagnose DSPWD, many of its symptoms are shared with "night owls' (LCPs). LCPs are categorized based on late sleep/wake timings, a delay in dim light melatonin onset (DLMO) and/or defective sleep homeostasis [16]. LCPs have been associated with higher scores for depression [17], decreased morning cognitive performance, excessive daytime sleepiness [18], variations in brain connectivity [ADD REF - Facer-Childs ER, Campos BM, Middleton B, Skene DJ, Bagshaw AP. Circadian phenotype impacts the brain's resting state functional connectivity, attentional performance and sleepiness. Sleep. 2019 Feb 15.], as well as increased morbidity and mortality rates [6]. Diurnal variations in both cognitive and physical performance measures have also been shown to vary between circadian phenotypes [19], with LCPs often having difficulties fitting into traditional working hours. Since around $50 \%$ of a given population would fall into a 'Late type' category (waking after 8:18 h) [20], one could propose that these individuals are compromised by having delayed circadian timing and could benefit by being shifted towards an earlier pattern.

Resetting biological clocks can be achieved using behavioural methods, pharmacological methods or a combination of the two. The human circadian system is responsive to light, which allows sleep/wake activity and physiology to adapt to the $24 \mathrm{~h}$ light dark cycle. As a result, light, or lack of light, is a major target to try and reset biological clocks through a process called photic entrainment. Bright light has been shown to shift circadian phase depending on time and duration of light administered (phase response curve) $[21,22]$. Exposure in the early morning phase advances the circadian system causing DLMO to peak earlier and sleep onset to become advanced [23]. Conversely, light exposure during the biological night creates a phase delay shown by a later DLMO [24,25].

Non photic forms of entrainment have also been researched to try and shift circadian phase [26]. These behavioural targets (ie, non-pharmacological interventions) include altering sleep/wake cycles [27], timed physical exercise [28] and timed feeding [29]. Timed feeding has been shown to shift peripheral clocks in mice without affecting the SCN clock [30]. Furthermore, timed feeding has been shown to regulate peripheral metabolic rhythms with a 5$\mathrm{h}$ delay in meal timings delaying rhythms of plasma glucose and adipose PER2 clock gene expression [29]. An alternative circadian zeitgeber that has been explored is targeted physical exercise. Timed exercise can alter the rhythm of core body temperature [31] and melatonin [32]. A recent paper has further supported these findings, showing that exercise in the morning and early afternoon elicits a phase advance, whereas scheduled evening exercise causes a phase delay [33].

The majority of our society has stringent work and schooling hours requiring attendance between the hours of 09:00 h and 17:00 h. Despite these traditional imposed social clock requirements, there has been some shift towards understanding biological constraints by allowing flexibility of working hours [34], as well as attempts to move school start times to fit to adolescents' notoriously late running biological clocks [35]. However, despite awareness of the consequences, there is still a long way to go to directly translate research outcomes and affect change in our rapidly evolving 'round the clock' society.

Although attempting a phase advance (shifting the clock earlier) using some of these methods has previously been shown in laboratory studies [28,36,37], field studies are lacking. Furthermore, investigating the impact on mental health and diurnal variations in performance have not yet been attempted in real world settings. Here we propose a novel intervention strategy for LCPs, many of whom suffer from chronic circadian misalignment or disrupted sleep homeostasis. Using simple, practical lifestyle changes, we aimed to phase advance sleep/wake timings, DLMO and time of peak cortisol awakening response. We hypothesised that if a phase advance is achieved this would improve self-rated measures of mental health (depression, anxiety and stress) as well as shift the timing of peak performance earlier, and thus improve simple indices of cognitive (reaction time) and physical (grip strength) performance at non-optimum times of day.

\section{Methods}

\subsection{Participants}

The study received a favourable ethical opinion from the University of Birmingham Research Ethics Committee, was performed in accordance with the Declaration of Helsinki and participants gave written informed consent before involvement. A total of 178 individuals completed the Munich ChronoType Questionnaire (MCTQ paper version [38]) to calculate corrected mid-sleep on free days $\left(\mathrm{MSF}_{\mathrm{sc}}\right)$. Participants classified as Late chronotypes using an age and gender matched MCTQ database were invited to take part in the study $(\mathrm{n}=49)$. Individuals were screened for no diagnoses of sleep or neurological disorders via self-report and were not taking any medications that affected sleep, melatonin and cortisol rhythms. A total of 29 individuals agreed to take part in the study, of which five were excluded based on medical history and two dropped out prior to starting the study.

The final sample consisted of 22 healthy individuals ( 15 female, aged $21.3 \pm 3.3$ years, MSF $_{\mathrm{sc}}$ 06:52 \pm 00:17 h). The study used a randomized control trial design and was conducted over six weeks for each participant which took place between April and June 2016 (sunrise range 06:42 h to 04:40 h, sunset range 19:41 h to 21:32 h, latitude $52^{\circ} 29^{\prime} 22.0956^{\prime \prime} \mathrm{N}$ ). Participants were randomly assigned to the experimental ( $\mathrm{n}=12,9$ female) or control ( $\mathrm{n}=10,6$ female) groups at the start of the study. Two weeks of acclimatisation was used to assess habitual sleep patterns using actigraphy and gather questionnaire data at baseline (pre-intervention). Following this period, participants were asked to provide saliva samples for melatonin and cortisol in their home environment (details below) before attending the laboratory for testing sessions at 14:00 h, 20:00 $\mathrm{h}$ and 08:00 $\mathrm{h}$. To simulate a 'real world' setting, participants were able to leave the laboratory between testing sessions. Participants were then given a schedule to follow for the next three weeks (intervention) before returning to repeat all testing sessions, physiological sampling and questionnaires (Fig. 1). Participants completed the test sessions on the same day pre- and postintervention. Summary details of participants' data preintervention for experimental and control groups to confirm accurate matching can be found in Supplemental Table 1. 


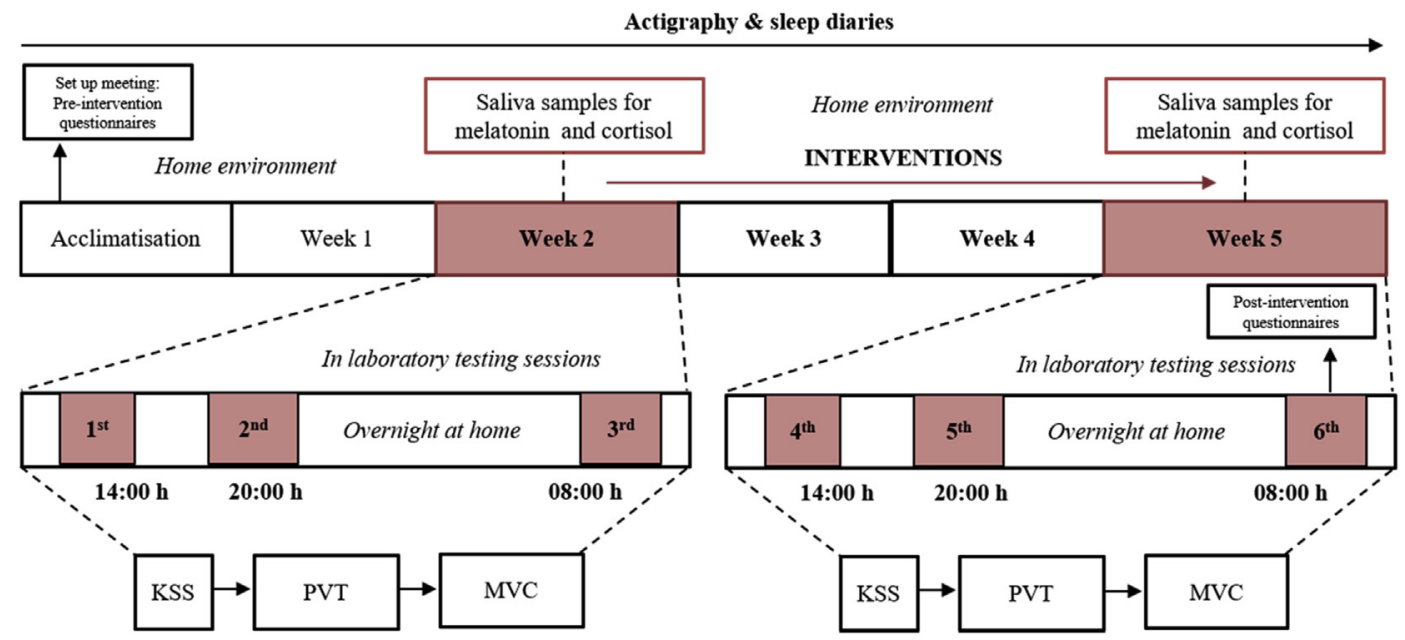

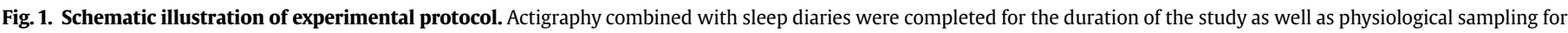

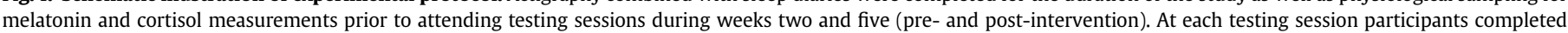

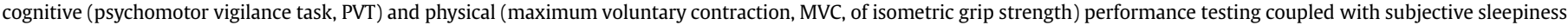
ratings using the Karolinska Sleepiness Scale (KSS).

\subsection{Non-pharmacological interventions}

At the final pre-intervention testing session, the experimental group were given an intervention schedule to follow for a period of three weeks. These interventions followed standard sleep hygiene suggestions and targeted appropriately timed light exposure, sleep, meals, caffeine and exercise (summarised in Table 1). The control group were given a placebo single instruction to 'eat lunch at the same time every day' with the assumption that there would be no differences in sleep timings and hence no effect on circadian phase. Adherence to the intervention was monitored through self-report. Meal timings pre- and post-intervention were collected as part of a diet questionnaire which enquired about food intake habits over the prior 2 weeks. Timing of naps were monitored through daily sleep diaries. A feedback questionnaire was administered at the end of the study where participants were asked whether they adhered to the intervention schedule on a scale of 0 (not at all) to 10 (completely). At each testing session participants answered an online questionnaire to record timing of external variables prior to/ between sessions such as caffeine intake, exercise and meal times.

\subsection{Physiological data}

All participants underwent training in how to collect saliva samples in their home environment following strict protocols. During the sampling period, participants were asked to refrain from cleaning their teeth, drinking caffeinated drinks, alcoholic drinks or any drinks that contained artificial colouring. Each individual was provided with a sample record collection form in order to report the exact times that samples were given and report any factors that could have affected the sampling period (eg, exposure to light) disruption to sampling. Participants provided saliva samples during one morning and one evening during pre-intervention (week two) and post-intervention (week five). Samples for melatonin were collected whilst seated in dim lighting conditions (ie, no overhead lights, no electronic devices and curtains closed) every 30 min from between $3 \mathrm{~h}$ and $4 \mathrm{~h}$ prior to habitual bedtime until $1 \mathrm{~h}$ after habitual bedtime. Morning samples for cortisol were collected over a period of $3 \mathrm{~h}$ from wake-up time (the first five samples every $15 \mathrm{~min}$ and the remaining four samples every $30 \mathrm{~min}$ ). Exact sampling times for each individual were recorded.

Table 1

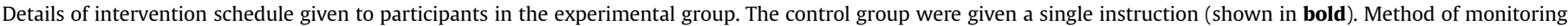
adherence (in addition to a feedback questionnaire administered post-intervention) is given for each intervention target.

\begin{tabular}{|c|c|c|}
\hline Intervention target & Instructions given & How adherence was monitored \\
\hline Wake up time & $\begin{array}{l}\text { Participants were asked to try and wake up } 2-3 \text { h before habitual } \\
\text { wake up time. } \\
\text { Participants were asked to maximise outdoor light exposure during } \\
\text { the mornings. }\end{array}$ & $\begin{array}{l}\text { Continuous monitoring pre- and post-intervention through actigraphy and } \\
\text { sleep diaries. }\end{array}$ \\
\hline Sleep/wake timings & $\begin{array}{l}\text { Participants were asked to try and keep sleep/wake times fixed } \\
\text { (within } 15 / 30 \mathrm{~min} \text { ) between workdays and free days. }\end{array}$ & $\begin{array}{l}\text { Continuous monitoring pre- and post-intervention through actigraphy and } \\
\text { sleep diaries. }\end{array}$ \\
\hline Sleep onset & $\begin{array}{l}\text { Participants were asked to try and go to sleep } 2-3 \text { h before habitual } \\
\text { bedtime. } \\
\text { Participants were asked to limit light exposure during the evenings. }\end{array}$ & $\begin{array}{l}\text { Continuous monitoring pre- and post-intervention through actigraphy and } \\
\text { sleep diaries. }\end{array}$ \\
\hline Diet/nutrition & $\begin{array}{l}\text { Participants were asked to keep a regular schedule for daily meals. } \\
\text { Participants were asked to have breakfast as soon after wake up as } \\
\text { possible. } \\
\text { Participants were asked to eat lunch at the same time every day. } \\
\text { Participants were asked not to have dinner after } 19: 00 \mathrm{~h} \text {. }\end{array}$ & $\begin{array}{l}\text { An online questionnaire was completed at all testing sessions to record time } \\
\text { since last meal. }\end{array}$ \\
\hline Caffeine intake & Participants were asked not to drink any caffeine after 15:00 h. & $\begin{array}{l}\text { An online questionnaire was completed at all testing sessions to record time } \\
\text { since caffeine intake. }\end{array}$ \\
\hline Power naps & Participants were asked not to nap after 16:00 h. & Napping was recorded through self-reported daily sleep diaries. \\
\hline Exercise & $\begin{array}{l}\text { If exercise was part of an individual's usual routine they were asked } \\
\text { to schedule this during the morning. }\end{array}$ & $\begin{array}{l}\text { An online questionnaire was completed at all testing sessions to record time } \\
\text { since exercise. }\end{array}$ \\
\hline
\end{tabular}


Radioimmunoassays (RIA) of melatonin and cortisol in human saliva were performed (Stockgrand Ltd, University of Surrey) using an Iodine ${ }^{125}$ radioactive labelled tracer and solid phase separation [39]. Individual DLMOs were calculated with a linear response function using the mean of the individual baseline concentration values plus two standard deviations of the mean. The time of highest cortisol concentration recorded during the sampling period was used as an indicator of peak cortisol awakening response. Due to insufficient or contaminated samples paired DLMO values (preand post-intervention) could not be computed for three subjects in the experimental group and five subjects in the control group.

\subsection{Behavioural data}

\subsubsection{Sleep Analysis}

Actigraphs (Actiwatch $\AA$ Light, 2006, CamNtech), combined with daily sleep diaries, were worn on the non-dominant wrist for the entire duration of the study (weeks $1-5$ ) to monitor actigraphic sleep and rest-activity patterns (1-min epochs) in the home environment and analysed with the manufacturer's software (Sleep Analysis 7.23, Cambridge Neurotechnology Ltd). Due to incorrect wearing of the devices, actigraphic data from two individuals (one in the experimental group and one in the control group) were not useable.

\subsubsection{Questionnaires}

A set of questionnaires were completed by each participant during a set up meeting pre-intervention and repeated at the end of the final testing session (post-intervention). Questionnaires included the MCTQ paper version [38], Epworth Sleepiness Scale (ESS) [40], Pittsburgh Sleep Quality Index (PSQI) [41], Profile of Mood States (POMS) [42], Depression, Anxiety and Stress Scale (DASS) [43], and a Diet Questionnaire [29]. Due to insufficient completion of questionnaires, three individuals' results were not recorded for POMS, two for DASS and two for the Diet Questionnaire.

\subsubsection{Sleepiness}

Daytime subjective sleepiness, measured using the Karolinska Sleepiness Scale (KSS) [44], was assessed at each testing session before the cognitive and physical tasks were performed.

\subsubsection{Reaction time}

Cognitive testing consisted of a 2-min visual psychomotor vigilance task (PVT) [45]. The PVT was conducted on a desktop computer (DQ670W, Intel ${ }^{\circledR}$ Core ${ }^{\mathrm{TM}}$ i7-2600 processor, 4 GB RAM, 32-bit Windows 7) with a standard keyboard and mouse. The same set up was used throughout the study for each participant and each testing session. Participants also performed three trial tests during the acclimatisation phase to familiarise themselves with the set up and minimise learning effects. Milliseconds were recorded for each trial, then a mean response time was taken over the number of trials.

\subsubsection{Grip strength}

To obtain a simple measure of physical performance an electronic hand dynamometer (EH101, CAMRY) was used to perform a $6 \mathrm{~s}$ maximum voluntary contraction (MVC) test of isometric grip strength [46]. Participants stood with the elbow extended at $180^{\circ}$ and used their dominant hand in a pronated position to apply as much grip pressure as possible. Raw scores were recorded in $\mathrm{kg}$. Three trials were completed with 2 min rest between each trial and the highest recorded value was used in the subsequent analysis. A set script was used to motivate the participants due to the influence of motivation on performance [47].

\subsection{Statistical analysis}

Statistical comparisons were performed in GraphPad Prism (version 7.00), using linear regression analysis and two-way repeated measures ANOVA with post hoc tests corrected for multiple comparisons, adding intervention group (experimental/control), assessment period (pre-vs. post-intervention) or time of day (08:00 h, 14:00 h and 20:00 h) as factors. Diurnal variations in performance and sleepiness variables were plotted using second degree polynomial regression curves. Due to data collection occurring at 14:00 h through to $08: 00 \mathrm{~h}$, the model is constrained to this time period.

The raw scores for the performance measurements (reaction time in milliseconds from the PVT and grip strength in kilograms from the MVC test) were normalised by converting to percentages relative to each individual's time of peak performance. For example, the testing session where fastest reaction time and strongest grip strength was recorded was designated as $100 \%$ for that participant. The subsequent scores were calculated relative to this. Higher percentages always relate to better performance achieved (faster reaction time and stronger grip strength). This was to allow diurnal variations to be quantified in a standardised way across individuals and across different measures of performance $[19,48]$. These data were normalised relative to each individual in the pre- and postintervention conditions separately. Test statistics are given to one significant figure. Significance levels are displayed as ns $=$ not significant, $\mathrm{p}<0.05={ }^{*}, \mathrm{p}<0.01={ }^{* *}, \mathrm{p}<0.001={ }^{* * *}$ and $\mathrm{p}<0.0001={ }^{* * * *}$. Values are represented as the mean \pm standard error of the mean (SEM) unless specified otherwise (age and BMI values are given with standard deviations). Exact $\mathrm{p}$ values are given to two significant figures, apart from when significance is identified as less than 0.0001 , in which case $\mathrm{p}<0.0001$ is reported. The 08:00 $\mathrm{h}$ test is described as morning, 14:00 $\mathrm{h}$ as afternoon and 20:00 $\mathrm{h}$ as evening. Reaction time (measured using the PVT) will be referred to as a simple index of attentional cognitive performance and isometric grip strength (measured using an MVC test) as a simple index of physical performance.

\section{Results}

To confirm that the study groups were evenly matched according to the range of variables discussed below, all data were initially compared pre-intervention and no significant differences were found in any of the parameters measured (Supplemental Table 1). Experimental and control groups were of similar age $(21.7 \pm 2.8$ and $20.9 \pm 3.9$ years $)$, BMI $(22.9 \pm 3.2$ and $22.6 \pm 2.1)$ and $\mathrm{MSF}_{\mathrm{Sc}}(07: 15 \mathrm{~h} \pm$ 00:27 and 06:02 $\mathrm{h} \pm$ 00:14). At baseline (preintervention) significant linear relationships were observed between $\mathrm{MSF}_{\mathrm{sc}}$ and wake up time $\left(\mathrm{R}^{2}=0.53, \mathrm{~F}=21.21, \mathrm{p}=0.0002\right)$, sleep onset $\left(R^{2}=0.40, F=12.69, p=0.0021\right)$, peak time of the cortisol awakening response $\left(\mathrm{R}^{2}=0.39, \mathrm{~F}=12.65, \mathrm{p}=0.002\right)$, and DLMO $\left(R^{2}=0.33, F=5.98, p=0.03\right)$ (Fig. 2). These results support and validate the classification of participants as LCPs through actigraphic analyses and biological phase markers following the original identification as Late chronotypes from the MCTQ.

\subsection{Adherence to interventions}

Overall, the experimental group reported on average $7.8 \pm 0.7$ adherence to the interventions in the feedback questionnaire. Adherence to interventions targeting sleep/wake and dietary variables (monitored through actigraphy and a diet questionnaires) were confirmed with an advance in timings (see below). Avoidance of naps after 16:00 h was confirmed using self-reported sleep diaries. Results from the online questionnaire at the evening testing 

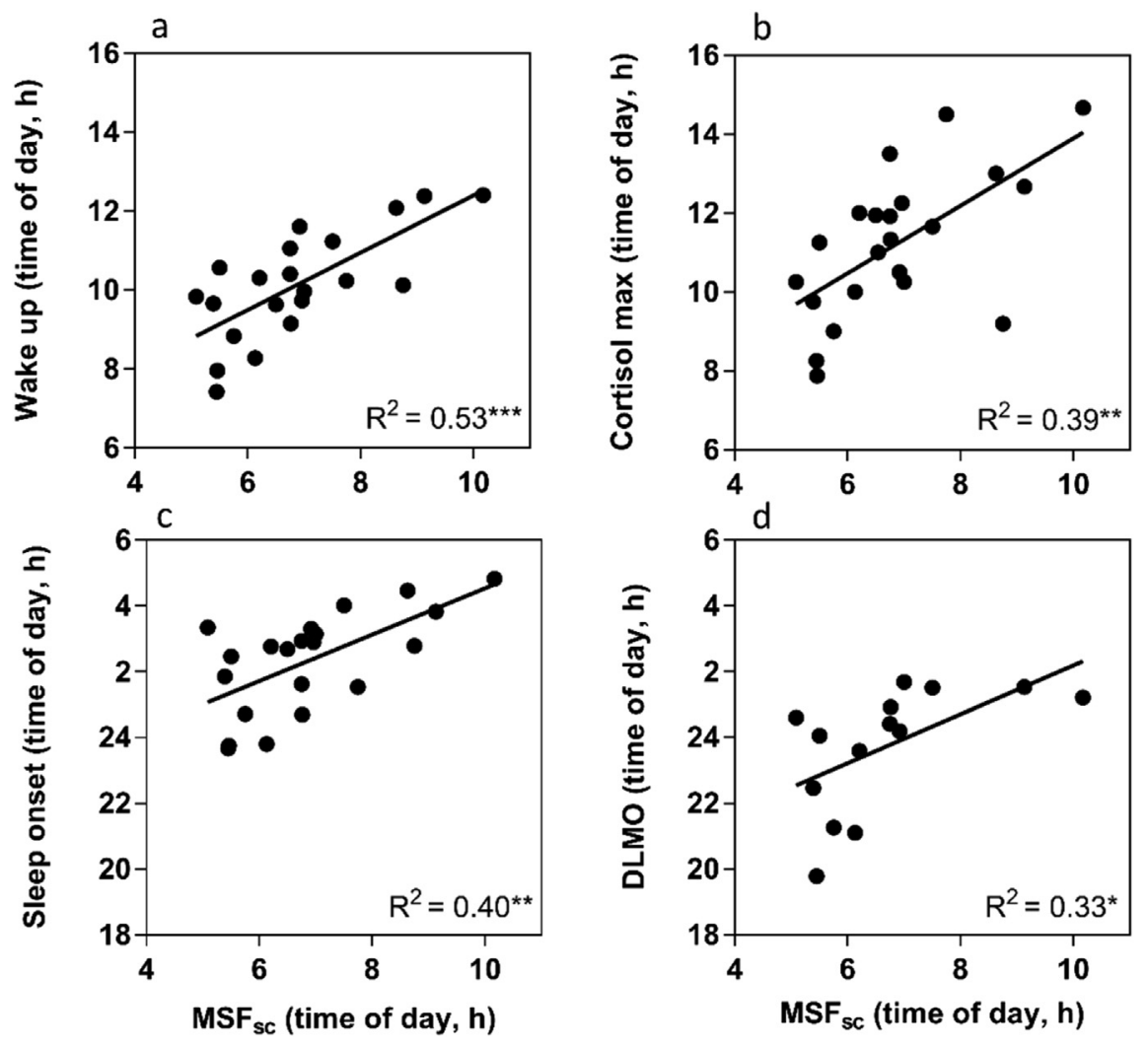

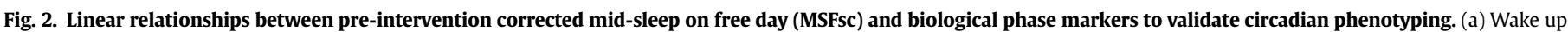

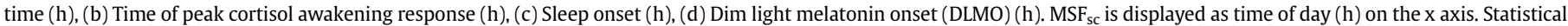

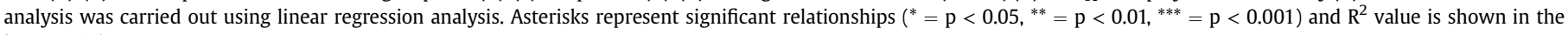
bottom right corner.

session confirm an advance in self-reported timing of caffeine intake, exercise and last meal for the experimental group postintervention. Average self-reported caffeine intake before the 20:00 h testing session was on average 4 hours earlier post-intervention in the experimental group $(5.9 \pm 1.7 \mathrm{~h}$ pre-intervention and $10.3 \pm 1.5 \mathrm{~h}$ post-intervention), meaning this advanced from 14:00 $\mathrm{h}$ to $10: 00 \mathrm{~h}$. Average self-reported hours since exercise advanced from $6.8 \pm 1.7 \mathrm{~h}$ before the evening test session preintervention to $7.8 \pm 1.8 \mathrm{~h}$ before the evening test session postintervention, as did hours since last meal from $2.4 \pm 0.4 \mathrm{~h}$ preintervention to $3.8 \pm 0.8$ hrs post intervention. By contrast, the control group had a slight delay in timings of exercise and meal time relative to pre-intervention $(6.0 \pm 1.9 \mathrm{~h}$ to $4.8 \pm 1.8 \mathrm{~h}$ and $3.5 \pm 1.0 \mathrm{~h}$ to $2.8 \pm 0.8 \mathrm{~h}$ respectively) and a slight advance in hours in caffeine from $6.1 \pm 2.3 \mathrm{~h}$ to $8.7 \pm 2.6 \mathrm{~h}$.

\subsection{Phase advance}

Compared to pre-intervention, a clear phase advance of around $2 \mathrm{~h}$ was observed post-intervention in the experimental group, as measured by the MCTQ actigraphy and circadian phase markers (Fig. 3 and Table 2). MSF sc $_{\text {sa }}$ whifted significantly earlier by $2.57 \pm 0.32 \mathrm{~h}(\mathrm{p}<0.0001)$. This advance was confirmed with actigraphic analysis showing a significant advance of $1.73 \pm 0.28 \mathrm{~h}$ for sleep onset and $1.92 \pm 0.26 \mathrm{~h}$ for wake-up time (both $\mathrm{p}<0.0001$ ), with no significant changes in sleep duration, sleep efficiency or sleep latency. DLMO was advanced by $1.96 \pm 0.63 \mathrm{~h}$ $(\mathrm{p}=0.018)$, and time of peak cortisol awakening response by $2.22 \pm 0.50 \mathrm{~h}(\mathrm{p}=0.0005)$. There were no significant changes in phase angle (time between sleep onset and DLMO). Average selfreported breakfast time in the experimental group shifted significantly earlier by $1.11 \pm 0.39 \mathrm{~h}$ compared to pre-intervention $(\mathrm{p}=0.022)$. Similarly, average self-reported lunch and dinner times also advanced by $0.75 \pm 0.27 \mathrm{~h}$ (lunch, $\mathrm{p}=0.023$ ) and $1.44 \pm 0.49 \mathrm{~h}$ (dinner, $\mathrm{p}=0.021)$. In the control group there was a significant delay of $1.16 \pm 0.34 \mathrm{~h}$ in sleep onset $(\mathrm{p}=0.0067)$ and $1.24 \pm 0.32 \mathrm{~h}$ in wake-up time $(\mathrm{p}=0.0021)$ compared to preintervention. By contrast to the experimental group, no other variables were significantly different in the control group postintervention.

\subsection{Impact of interventions on mental well-being}

Subjective ratings of depression and stress significantly decreased following the interventions in the experimental group (Fig. 4 and Table 2). Overall DASS score decreased by $8.7 \pm 2.4$ points from 19.8 to 11.2 (pre-intervention). Splitting DASS into depression, anxiety and stress scores separately revealed a significant effect of intervention $(\mathrm{F}(1,11)=13.28, \mathrm{p}=0.0039)$, and significant decreases in the depression and stress elements but not anxiety $(\mathrm{p}=0.37)$. Depression was reduced from $5.5 \pm 1.0$ to $2.3 \pm 1.2(\mathrm{p}=0.025)$, and stress from $9.5 \pm 2.2$ to $5.7 \pm 1.9$ $(\mathrm{p}=0.0061)$. There were no significant differences found for the control group in any parameters measured. In both study groups no significant differences were observed for POMS, PSQI or ESS (Fig. 4 and Table 2).

\subsection{Impact of interventions on performance and sleepiness}

Using second order polynomial regression analysis, peak performance and sleepiness times were identified from best fit diurnal variation curves (Fig. 5). Within the constraints of the model 

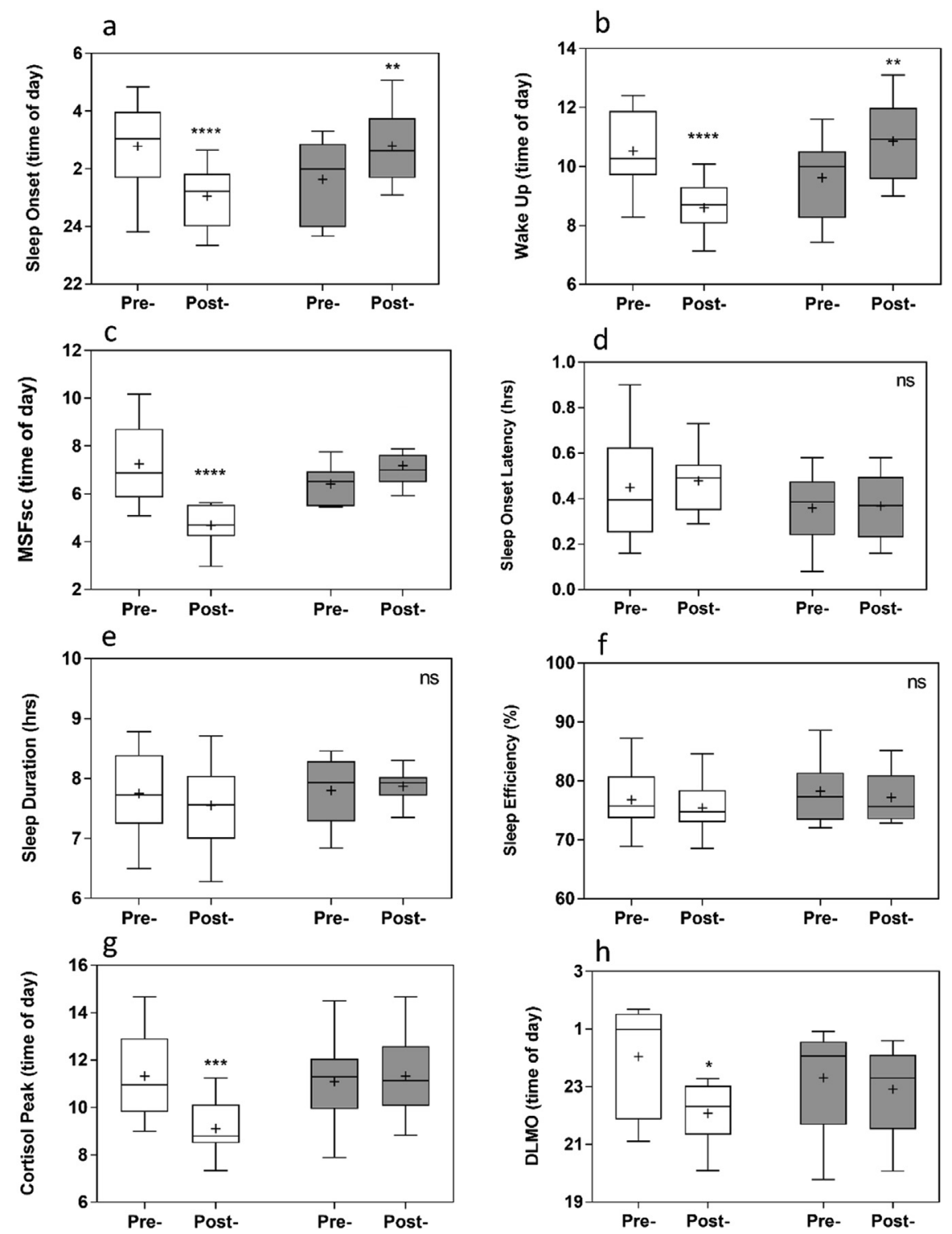

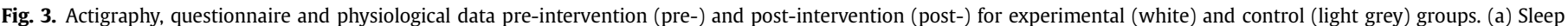

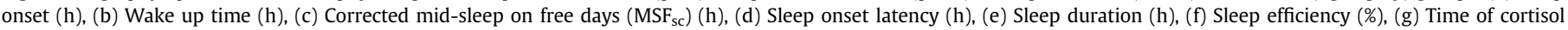

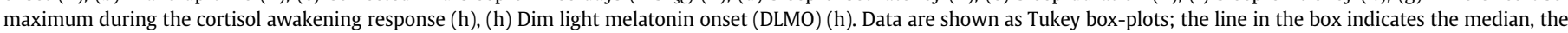

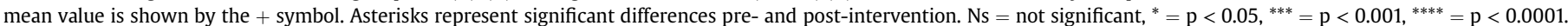

(08:00 h to 20:00 h), sleepiness was highest at 08:00 $\mathrm{h}$ for both the experimental and control groups pre- and post-intervention. At the pre-intervention testing, strongest grip strength in the experimental group occurred at the 20:00 $\mathrm{h}$ testing session which advanced to $15: 21 \mathrm{~h}$ post-intervention. In the control group, timing of peak grip strength was delayed from 17:12 h to 20:00 h postintervention. The same was seen for the PVT with fastest reaction time advancing in the experimental group from 20:00 $\mathrm{h}$ to $12: 30 \mathrm{~h}$ and delaying in the control group from 15:48 h to 19:48 h.

There was a significant reduction in inter-individual variation of performance in the experimental group but no significant changes in the control group. During pre-intervention testing, average grip strength varied by $14.2 \%$ in the experimental group, which was reduced to $7.2 \%$ post-intervention $(\mathrm{p}=0.0024)$. The same was seen for reaction time with average inter-individual differences reduced from $13.0 \%$ pre-intervention to $4.4 \%$ post-intervention $(\mathrm{p}=0.028$ ).

A significant interaction of time of day and intervention was found for sleepiness in the experimental group $(F(2,22)=3.44$, $\mathrm{p}=0.049)$ as well as main effects of time of day $(\mathrm{F}(2,22)=11.41$, $\mathrm{p}=0.0004)$ and interventions $(\mathrm{F}(2,11)=5.36, \mathrm{p}=0.041)$. Following interventions, sleepiness was lower at 08:00 h ( $4.6 \pm 0.6$ vs $6.3 \pm 0.3)$ and $14: 00 \mathrm{~h}(3.6 \pm 0.5$ vs $4.7 \pm 0.5)$ but these differences were only significant at $08: 00 \mathrm{~h}(\mathrm{p}=0.0061)$. The experimental group also showed a significant main effect of time of day on grip strength performance $(\mathrm{F}(2,22)=21.73, \mathrm{p}<0.0001)$, as well as a significant main effect of interventions $(\mathrm{F}(1,11)=4.94, \mathrm{p}=0.048)$ and an interaction effect $(\mathrm{F}(2,22)=9.19, \mathrm{p}=0.0013)$. Post hoc tests revealed that grip strength at both $08: 00 \mathrm{~h}$ and 14:00 $\mathrm{h}$ significantly improved following interventions ( $p=0.015$ and $p=0.0075$ respectively). For PVT performance, there was a main effect of time of day ( $F$ $(2,22)=3.85, \mathrm{p}=0.037)$ but not interventions. The interaction was found to be significant, however $(\mathrm{F}(2,22)=7.93, \mathrm{p}=0.0026)$. Reaction time at 08:00 $\mathrm{h}$ was significantly faster after interventions ( $p=0.017$ ) but there was no change at 14:00 h or 20:00 h.

In the control group, a significant main effect of time of day was found for sleepiness $(F(2,18)=8.86, p=0.0021)$, MVC ( $F$ 
Table 2

Summary of main variables and statistical analysis for the experimental group and control group pre- and post-intervention. ${ }^{\mathrm{a}}$

\begin{tabular}{|c|c|c|c|c|c|c|c|}
\hline \multirow[t]{2}{*}{ Variable measured } & \multicolumn{2}{|c|}{ Experimental group } & \multicolumn{2}{|l|}{ Control group } & \multirow{2}{*}{$\begin{array}{l}\text { Interaction } \\
\text { (intervention group } \\
\text { and assessment period) }\end{array}$} & \multirow{2}{*}{$\begin{array}{l}\text { Main Effect of } \\
\text { Intervention Group } \\
\text { (experimental vs. } \\
\text { control) }\end{array}$} & \multirow{2}{*}{$\begin{array}{l}\text { Main Effect of } \\
\text { Assessment Period } \\
\text { (pre- vs post- } \\
\text { intervention) }\end{array}$} \\
\hline & $\begin{array}{l}\text { Pre- } \\
\text { intervention }\end{array}$ & $\begin{array}{l}\text { Post- } \\
\text { intervention }\end{array}$ & $\begin{array}{l}\text { Pre- } \\
\text { intervention }\end{array}$ & $\begin{array}{l}\text { Post- } \\
\text { intervention }\end{array}$ & & & \\
\hline $\begin{array}{l}\text { Corrected mid-sleep on } \\
\text { free days (MSF } \text { sc }) \\
\text { (hh:mm) }\end{array}$ & $07: 15 \pm 00: 27$ & $04: 40 \pm 00: 15$ & $06: 02 \pm 00: 14$ & $07: 10 \pm 00: 18$ & $\mathrm{~F}(1,20)=50.8^{* * * *}$ & $\mathrm{~F}(1,20)=3.9^{\mathrm{ns}}$ & $\mathrm{F}(1,20)=14.8^{* *}$ \\
\hline \multicolumn{8}{|c|}{ Nutrition related variables } \\
\hline $\begin{array}{l}\text { Average days per week } \\
\text { eating breakfast } \\
\text { (days) }\end{array}$ & $4.1 \pm 0.6$ & $5.4 \pm 0.5$ & $4.7 \pm 0.8$ & $4.4 \pm 0.8$ & $\mathrm{~F}(1,19)=4.1^{\mathrm{ns}}$ & $\mathrm{F}(1,19)=0.04^{\mathrm{ns}}$ & $\mathrm{F}(1,19)=1.6^{\mathrm{ns}}$ \\
\hline $\begin{array}{l}\text { Average breakfast time } \\
\quad(\mathrm{hh}: \mathrm{mm})\end{array}$ & $10: 33 \pm 00: 25$ & $09: 24 \pm 00: 24$ & $10: 01 \pm 00: 34$ & $10: 41 \pm 00: 20$ & $\mathrm{~F}(1,18)=9.2^{* *}$ & $\mathrm{~F}(1,18)=0.4^{\mathrm{ns}}$ & $\mathrm{F}(1,18)=0.6^{\mathrm{ns}}$ \\
\hline $\begin{array}{l}\text { Average lunch time } \\
\quad(\text { hh:mm })\end{array}$ & $14: 36 \pm 00: 30$ & $13: 51 \pm 00: 27$ & $13: 27 \pm 00: 17$ & $13: 39 \pm 00: 19$ & $\mathrm{~F}(1,18)=6.4^{*}$ & $\mathrm{~F}(1,18)=1.6^{\mathrm{ns}}$ & $\mathrm{F}(1,18)=2.1^{\mathrm{ns}}$ \\
\hline $\begin{array}{l}\text { Average dinner time } \\
\quad(\mathrm{hh}: \mathrm{mm})\end{array}$ & $20: 07 \pm 00: 45$ & $18: 41 \pm 00: 14$ & $18: 49 \pm 00: 17$ & $19: 06 \pm 00: 20$ & $\mathrm{~F}(1,15)=6.5^{*}$ & $\mathrm{~F}(1,15)=0.7^{\mathrm{ns}}$ & $\mathrm{F}(1,15)=3.0^{\mathrm{ns}}$ \\
\hline \multicolumn{8}{|c|}{ Mental well-being variables } \\
\hline $\begin{array}{l}\text { Pittsburgh Sleep } \\
\text { Quality Index (PSQI) }\end{array}$ & $4.8 \pm 0.7$ & $4.2 \pm 0.7$ & $5.3 \pm 0.8$ & $4.8 \pm 0.5$ & $\mathrm{~F}(1,20)=0.02^{\mathrm{ns}}$ & $\mathrm{F}(1,20)=0.4^{\mathrm{ns}}$ & $\mathrm{F}(1,20)=1.1^{\mathrm{ns}}$ \\
\hline $\begin{array}{l}\text { Profile of Mood States } \\
\quad \text { (POMS) }\end{array}$ & $10.3 \pm 6.2$ & $-2.9 \pm 4.5$ & $8.5 \pm 5.7$ & $7.1 \pm 6.1$ & $\mathrm{~F}(1,17)=2.2^{\mathrm{ns}}$ & $\mathrm{F}(1,17)=0.3^{\mathrm{ns}}$ & $\mathrm{F}(1,17)=3.4^{\mathrm{ns}}$ \\
\hline $\begin{array}{l}\text { Epworth Sleepiness } \\
\text { Scale (ESS) }\end{array}$ & $7.1 \pm 1.2$ & $6.3 \pm 1.1$ & $9.0 \pm 1.0$ & $8.7 \pm 0.7$ & $\mathrm{~F}(1,20)=0.2^{\mathrm{ns}}$ & $\mathrm{F}(1,20)=2.8^{\mathrm{ns}}$ & $\mathrm{F}(1,20)=0.7^{\mathrm{ns}}$ \\
\hline $\begin{array}{l}\text { Depression Anxiety and } \\
\text { Stress Scale (DASS) }\end{array}$ & $19.8 \pm 3.4$ & $11.2 \pm 3.1$ & $13.8 \pm 3.7$ & $13.6 \pm 5.0$ & $\mathrm{~F}(1,18)=2.6^{\mathrm{ns}}$ & $\mathrm{F}(1,18)=2.0^{\mathrm{ns}}$ & $\mathrm{F}(1,18)=5.2^{*}$ \\
\hline \multicolumn{8}{|l|}{ Actigraphy variables } \\
\hline Sleep Onset (hh:mm) & $02: 46 \pm 00: 26$ & $01: 03 \pm 00: 18$ & $01: 37 \pm 00: 30$ & $02: 47 \pm 00: 27$ & $\mathrm{~F}(1,18)=42.7^{* * * *}$ & $\mathrm{~F}(1,18)=0.3^{\mathrm{ns}}$ & $\mathrm{F}(1,18)=1.7^{\mathrm{ns}}$ \\
\hline $\begin{array}{l}\text { Wake Up Time } \\
\text { (hh:mm) }\end{array}$ & $10: 31 \pm 00: 23$ & $08: 36 \pm 00: 15$ & $09: 37 \pm 00: 29$ & $10: 51 \pm 00: 29$ & $\mathrm{~F}(1,18)=59.6^{* * * *}$ & $\mathrm{~F}(1,18)=1.7^{\mathrm{ns}}$ & $\mathrm{F}(1,18)=2.8^{\mathrm{ns}}$ \\
\hline Sleep Duration (h) & $7.75 \pm 0.20$ & $7.55 \pm 0.20$ & $7.8 \pm 0.2$ & $7.9 \pm 0.1$ & $\mathrm{~F}(1,18)=0.9^{\mathrm{ns}}$ & $\mathrm{F}(1,18)=0.6^{\mathrm{ns}}$ & $\mathrm{F}(1,18)=0.2^{\mathrm{ns}}$ \\
\hline Sleep Efficiency (\%) & $76.80 \pm 1.48$ & $75.40 \pm 1.25$ & $78.3 \pm 1.9$ & $77.2 \pm 1.5$ & $\mathrm{~F}(1,18)=0.03^{\mathrm{ns}}$ & $\mathrm{F}(1,18)=0.7^{\mathrm{ns}}$ & $\mathrm{F}(1,18)=1.8^{\mathrm{ns}}$ \\
\hline \multicolumn{8}{|c|}{ Physiological variables } \\
\hline $\begin{array}{l}\text { Dim Light Melatonin } \\
\text { Onset (hh:mm) }\end{array}$ & $00: 02 \pm 00: 37$ & $22: 04 \pm 00: 21$ & $23: 18 \pm 00: 54$ & $22: 54 \pm 00: 45$ & $\mathrm{~F}(1,12)=2.2^{\mathrm{ns}}$ & $\mathrm{F}(1,12)=0.005^{\mathrm{ns}}$ & $\mathrm{F}(1,12)=5.0^{*}$ \\
\hline $\begin{array}{l}\text { Cortisol Peak Time } \\
\text { (hh:mm) }\end{array}$ & $11: 19 \pm 00: 31$ & $09: 06 \pm 00: 19$ & $11: 05 \pm 00: 36$ & $11: 19 \pm 00: 32$ & $\mathrm{~F}(1,20)=11.1^{* *}$ & $\mathrm{~F}(1,20)=2.7^{\mathrm{ns}}$ & $\mathrm{F}(1,20)=7.2^{*}$ \\
\hline
\end{tabular}

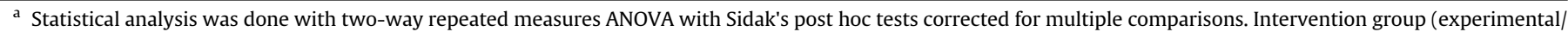

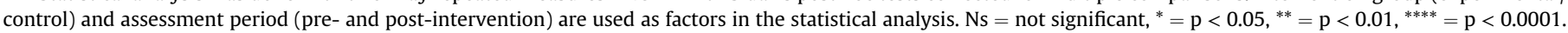
Values are shown as mean \pm SEM unless specified.

$(2,18)=14.73, \mathrm{p}=0.0002)$ and PVT $(\mathrm{F}(2,18)=3.63, \mathrm{p}=0.048)$ performance, but not for interventions or the interaction. Post hoc tests did not show any significant changes from pre-to post-intervention in the control group for any parameters.

\section{Discussion}

Researchers, clinicians and industry experts are constantly seeking ways to better understand how we can improve mental health, well-being and performance. One factor that seems constantly overlooked is the timing of behaviour (eg, sleeping, eating and working). Here we took a group of 'night owls' and attempted to reset their habitual late timings in behaviour in a realworld setting using simple, practical, non-pharmacological interventions. We show that a phase advance of around $2 \mathrm{~h}$ can be achieved which was accompanied by significant reductions in subjective ratings of depression and stress. In addition, elements of cognitive (reaction time) and physical (grip strength) performance significantly improved during 'non optimal' times, and diurnal peaks in performance occurred earlier in the day.

\subsection{Phase advance}

Actigraphy analysis revealed a significant advance in both actigraphic sleep onset and wake up time pre- to post-intervention in the experimental group. Sleep duration, latency and efficiency all remained similar pre- and post-intervention confirming that the earlier sleep onset was not associated with increased sleep latency and hence a curtailment of sleep duration. The behavioural impact of the intervention can therefore be attributed specifically to the shifting of sleep timing and not to an alteration of sleep homeostasis. In support of the actigraphy data, we also found a significant phase advance in melatonin onset (DLMO) of nearly $2 \mathrm{~h} \mathrm{(00:02} \mathrm{to}$ 22:04 h). This was coupled with a similar advance in peak timing of the cortisol awakening response that shifted from 11:19 to 09:06 h. Phase angle, measured as the time between DLMO and sleep onset, was also consistent pre- and post-intervention. By using gold standard biological phase markers, in addition to objective actigraphy, these results suggest a true circadian phase advance was observed in the experimental group following the interventions.

As light is the dominant zeitgeber of the circadian system it has been one of the main treatment options of CRSWDs such as DSWPD [49], and mood disorders (eg, seasonal affective disorder) [50]. Although controlled light exposure was not specifically administered in this study, participants were asked to wake up earlier and maximise exposure to morning light, thereby contributing to a phase advance in the circadian system. Simultaneously, the earlier sleep onset times observed combined with the instructions to decrease evening light exposure (eg, from room lighting and electronic devices) could have contributed to the delay in DLMO and sleep onset [51,52]. Timing of food intake could also be a factor influencing the phase advance. Meal timing 

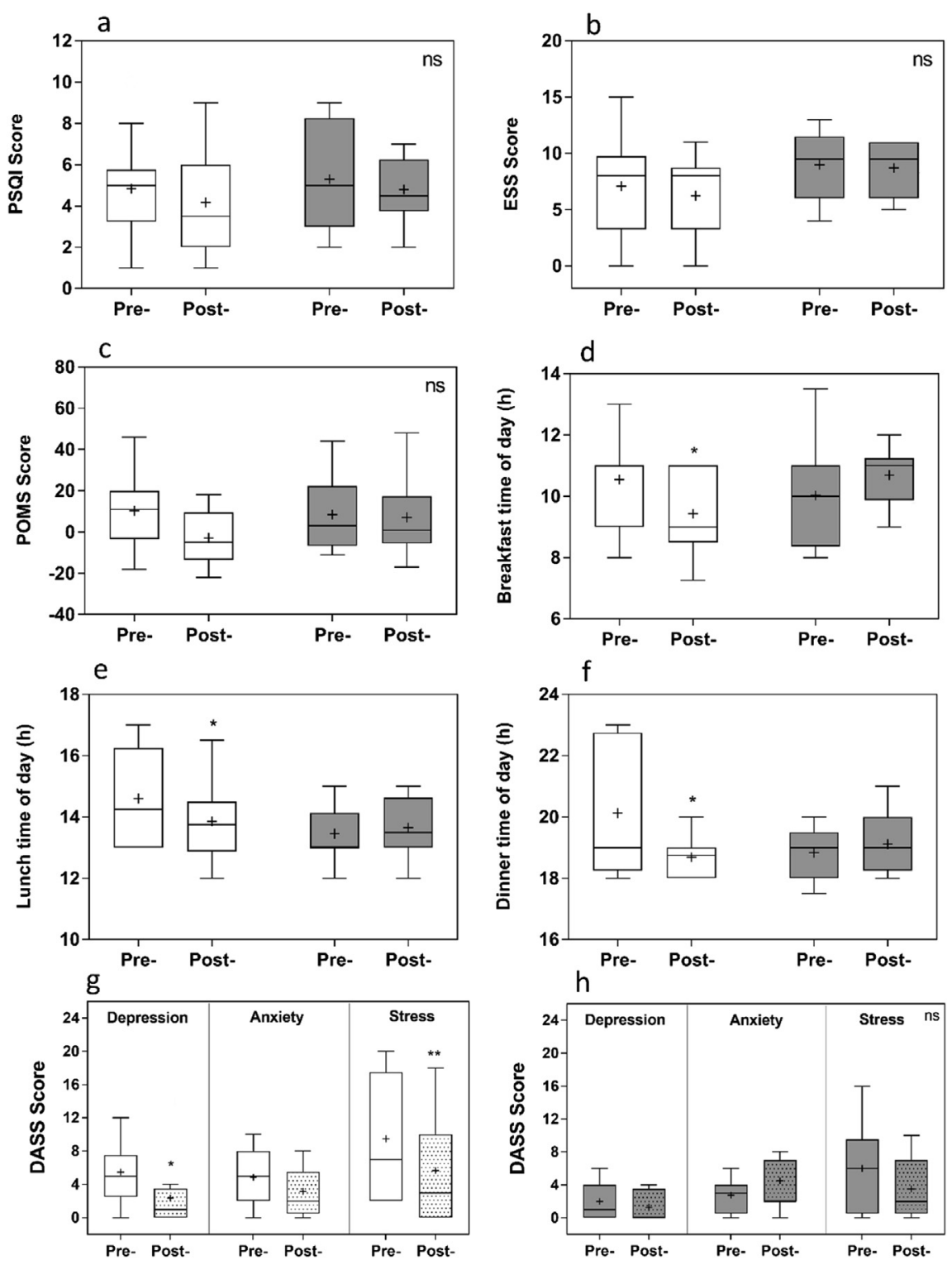

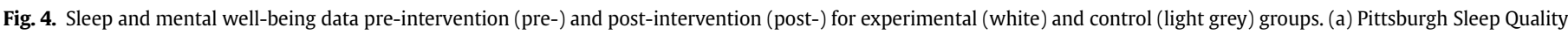

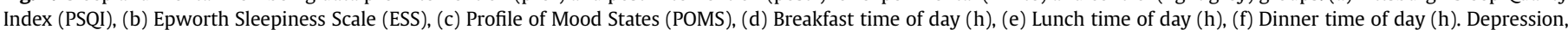

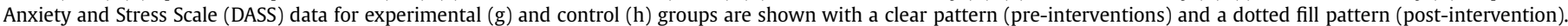

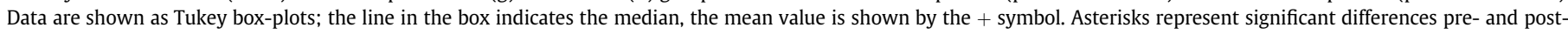
intervention. Ns $=$ not significant, ${ }^{*}=\mathrm{p}<0.05,{ }^{* *}=\mathrm{p}<0.01$.

has been suggested to have an entraining effect on the circadian system, in particular the peripheral clocks involved in metabolism [29]. Along with the importance of sleep for appetite regulation, studies have found that a morning carbohydrate rich meal can phase advance CBT [53]. There was a significant advance in average self-reported breakfast time (10:33 to 09:25 h) and an increase in the number of days/week breakfast was eaten, although this did not quite reach significance. The same was seen with average self-reported timing of lunch and dinner, which occurred significantly earlier post-intervention, allowing us to confirm adherence to the intervention requirement of not eating dinner after 19:00. These advances in meal times, which were observed in the experimental group but not the control group, could potentially be contributing to the advance in circadian timing. However, as the phase shifting effects of food were not measured directly in this study it remains speculative.

\subsection{Impact of interventions on mental well-being and performance}

The association of a delayed sleep phase with reduced mental health (eg, depression) has been shown in a number of independent studies [17,54,55]. Targeting sleep and circadian phase has also become a focus in the development of novel treatments in neuropsychological disorders. Following the interventions, we found a significant decrease in depression and stress score in the experimental group, indicative of better mental health. This was coupled with a similar trend in mood disturbances, with POMS score reducing from 10.33 to -2.89 , although this did not quite reach statistical significance. Notably, it was the depression and stress elements of the DASS scale that were reduced significantly, with anxiety score not being affected. Although anxiety and depression are two separate conditions with different diagnostic criteria, they are often comorbid. These results, however, suggest each factor is 

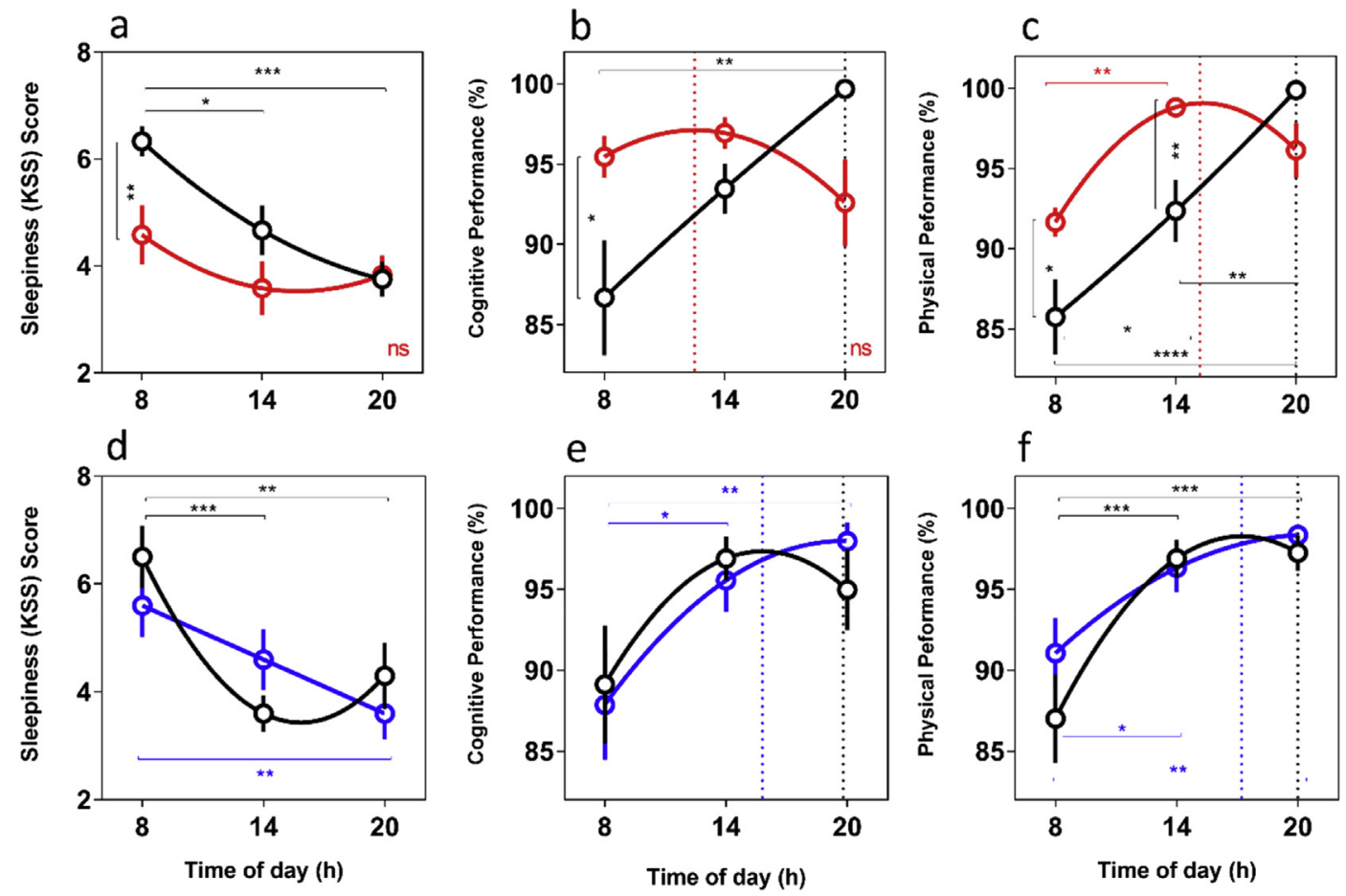

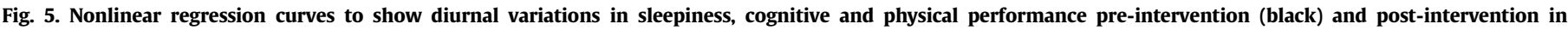

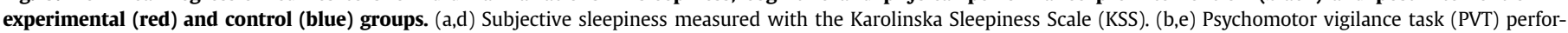

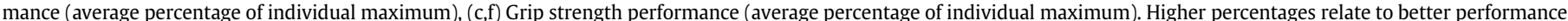

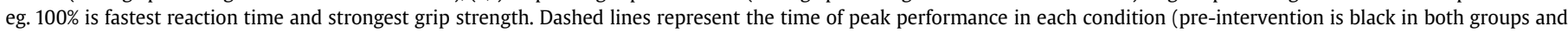

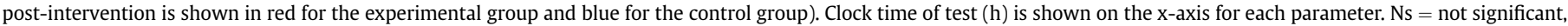
${ }^{*}=\mathrm{p}<0.05,{ }^{* *}=\mathrm{p}<0.01,{ }^{* * *}=\mathrm{p}<0.001$. (For interpretation of the references to colour in this figure legend, the reader is referred to the Web version of this article.)

affected independently, indicating separable relationships with sleep timing. This is consistent with the literature suggesting that the temporal relationship between anxiety/depression and reductions in sleep quality or quantity is also different (ie, anxiety generally preceding sleep issues, depression generally following sleep issues [56]). Being able to objectively explore these factors separately and identify the direction of causality would be an important future step within this work to determine the potential clinical usefulness of the approach for improving mental health.

Daytime sleepiness, measured here using the KSS, is one of the key factors associated with poor performance [57] and higher risk of errors [58]. Increased sleepiness, leading to lapses of concentration and even micro sleeps, has been proposed as a main influence in many of the vehicle-related incidents recorded annually [59]. Being able to reduce daytime sleepiness remains a leading motivation in both clinical settings and when considering performance/productivity in the real world [60-62]. Here we show that the experimental intervention significantly decreased daytime sleepiness at 08:00 $\mathrm{h}$ and at 14:00 h. Sleepiness was still at its highest in the morning, although significantly lower than preintervention. This near two-point difference in the morning means a change from 'some signs of sleepiness' to 'rather alert' (score of 6 to 4 on the KSS). There was a loss of significant diurnal variations in KSS score, similar to what was observed for reaction time and grip strength measures. The KSS score has previously been shown to correlate significantly with performance variables such as the PVT [63], as well as objective drowsiness [64]. Therefore, this intervention could prove useful to those professions that are generally more affected by sleepiness and require high vigilance such as air traffic control, lorry driving and aviation [65], especially since the risk of accidents has been shown to exhibit diurnal variation [66].
Understanding diurnal variations in performance has allowed some studies to shed light on the reason behind the high risk of motor accidents at non-optimal times of day [67], whilst others have examined the effect on performance in athletes [68,69]. In line with these suggestions, we now show the potential of manipulating these diurnal variations in night owls (ie, LCPs), producing a phase advance, to create a profile with peak performance occurring earlier in the day. There were significant improvements in reaction time (measured using a PVT) and isometric grip strength (measured using an MVC test) at 'non-optimal' morning times in the experimental group but not in the control group. The experimental group also showed a significant decrease in diurnal variations of sleepiness and performance variables. This reduction in amplitude is in line with previous research which showed a much larger range in performance differences for LCPs compared with ECPs $[68,70]$. The diurnal curves of reaction time and grip strength mirror the advance in sleep and circadian timings, with peak grip strength being shifted from 20:00 h to 15:21 h, and fastest reaction time occurring at 12:30 h instead of 20:00 h post-intervention.

\subsection{Limitations}

It is important to recognise that since we investigated relatively simple measures of cognitive (reaction time) and physical (grip strength) performance we should be cautious in over generalising how this intervention would impact more complex measures. Sleep deprivation studies [71,72] would suggest that more complex cognitive processes are likely to be affected, although the impact tends to be smaller. The PVT is a standard tool used in clinical and research settings to measure sustained attention, and has been shown to be sensitive to sleep loss and time of day [73], with minimal practice effects. Here we used a shortened version of the 
PVT (2-min vs $10 \mathrm{~min}$ ) which could have reduced the sensitivity to time of day effects, as pointed out by Basner, Mollicone [74]. An investigation into the validity of a $2 \mathrm{~min}$ and $5 \mathrm{~min}$ PVT, however, showed similar time of day relationships compared to the $10 \mathrm{~min}$ PVT, although overall reaction times were increased with task duration, as expected [45]. This can give us confidence that the time of day effects we observed in our study are reliable. Grip strength is a simple measure of muscle strength, which is frequently used as an evaluation of muscle function in exercise and clinical settings. MVC of isometric grip strength offers a robust approach to investigating contributions from central and peripheral mechanisms because the ability to produce maximal force relies on the capability of the muscle as well as the activation from the central nervous system [70]. Using isometric grip strength allows us to provide an insight into how this intervention can impact a simple index of physical performance. Previous research has correlated measures of muscle strength with sprint and jump performance [75]. However, performance itself is multifaceted and cannot be defined by one measure alone, so future work will need to explore how diurnal variations in different cognitive and physical performance tasks are influenced by this intervention.

We have relatively small sample sizes so further studies will be required to investigate how this intervention could impact larger cohorts and different populations. This also limits our ability to perform higher order analysis due to low power, which should be incorporated in future research in line with the discussion from Bland and Altman [76].

Although we were able to partially monitor adherence to the interventions, with the experimental group reporting 78\% adherence $(7.8 \pm 0.7$ out of 10$)$, this was mostly done by self-report. Since the control group were only asked to eat lunch at the same time each day, this was confirmed with no significant changes in timing of lunch reported in the diet questionnaire. A more tightly controlled experiment would have perhaps allowed more detailed assessment of each individual's behaviour and adherence to the protocol, however a strength of this study is that we were investigating individuals in a more realistic setting as opposed to artificial laboratory conditions.

Despite the value in using a real-world protocol due to its relative ease of implementation and less disruption to individuals' daily lives, it does limit the ability to control the many environmental and social influences that can have an impact. In addition, care should be taken when using these interventions to ensure that the timings do not risk overlapping with the delay period of the human phase response curve to light $[21,22]$. Therefore, these interventions should be implemented by a specialist due to the care needed in monitoring and planning the timings of intervention.

Constant routine and forced desynchrony protocols allow the characterisation of a truly endogenous rhythm through removing/ minimising the influence of external cues. The present study, however, was not aimed at finding endogenous components to performance and mental health measures but looked at the integrated system as a whole. The combination of endogenous circadian rhythms, sleep homeostasis, environmental cues and social schedules is what affects daily functioning and diurnal variations in the real world. Therefore, although we cannot attribute the changes we see strictly to one or other of these influences, we provide evidence that a practical intervention can phase advance night owls in a real life setting with positive outcomes on self-reported depression and stress, reaction time and grip strength.

\section{Conclusions}

Here we show the ability of a simple non-pharmacological intervention to phase advance night owls, reduce negative elements of mental health and sleepiness as well as manipulate peak performance times in the real world. These findings could yield considerable benefits in a number of different settings. Within the general population, of which a large proportion are night owls, these findings could offer a simple strategy to improve mental wellbeing and performance. Within clinical settings, further treatments for mental health in depression and stress could be explored specifically targeting circadian disruption without the need for pharmacological agents. This intervention could also be applied within more niche settings (eg, industry or sporting sectors) who have a key focus on developing strategies to maximise productivity and optimise performance. Despite the need for further research, this remains an exciting prospect for a society that is increasingly suffering from poor health, reduced mental well-being and under continuous pressure to achieve personal best performance.

\section{Author contributions}

E.F.C. and A.P.B. conceived of and designed the study with contributions from D.J.S. E.F.C collected and analysed the data. RIA analyses was performed by B.M. E.F.C wrote the manuscript with contributions from A.P.B and D.J.S. All other authors commented on the manuscript.

\section{Acknowledgements}

This work was supported by funding from the Biotechnology and Biological Sciences Research Council (BBSRC, BB/J014532/1) and the Engineering and Physical Sciences Research Council (EPSRC, EP/J002909/1). E.F.C was supported by a Wellcome Trust Institutional Strategic Support Fund (ISSF) Scheme accelerator fellowship (Wellcome 204846/Z/16/Z). Stockgrand Ltd provided the reagents for melatonin and cortisol measurements. Our sincere thanks are to all participants and to Dr Olivia Walch for her contribution to the study.

\section{List of abbreviations}

ECP Early circadian phenotype

LCP Late circadian phenotype

CBT Core body temperature

CRSWDs Circadian rhythm sleep-wake disorders

MSF $_{\text {sc }} \quad$ Corrected mid-sleep on free days

DLMO Dim light melatonin onset

KSS Karolinska Sleepiness Scale

PVT Psychomotor vigilance task

MVC Maximum voluntary contraction

\section{Conflict of interest}

B.M. and D.J.S. are co-directors of Stockgrand Ltd. The authors declare no other competing financial interests.

The ICMJE Uniform Disclosure Form for Potential Conflicts of Interest associated with this article can be viewed by clicking on the following link: https://doi.org/10.1016/j.sleep.2019.05.001.

\section{Appendix A. Supplementary data}

Supplementary data to this article can be found online at https://doi.org/10.1016/j.sleep.2019.05.001.

\section{References}

[1] Altevogt BM, Colten HR. Sleep disorders and sleep deprivation: an unmet public health problem. National Academies Press; 2006. 
[2] Aviva. Sleepless cities revealed as one in three adults suffer from insomnia. In: Aviva, editor. Aviva wellbeing report: aviva wellbeing report; 2017.

[3] Robertson MD, Russell-Jones D, Umpleby AM, et al. Effects of three weeks of mild sleep restriction implemented in the home environment on multiple metabolic and endocrine markers in healthy young men. Metabolism 2013;62:204-11.

[4] Refinetti R, Menaker M. The circadian rhythm of body temperature. Physiol Behav 1992;51:613-37.

[5] Dickinson DL, Wolkow AP, Rajaratnam SMW, et al. Personal sleep debt and daytime sleepiness mediate the relationship between sleep and mental health outcomes in young adults. Depress Anxiety; 2018.

[6] Knutson KL, von Schantz M. Associations between chronotype, morbidity and mortality in the UK Biobank cohort. Chronobiol Int 2018:1-9.

[7] Smith RS, Efron B, Mah CD, et al. The impact of circadian misalignment on athletic performance in professional football players. Sleep 2013;36: 1999-2001.

[8] Schaefer EW, Williams MV, Zee PC. Sleep and circadian misalignment for the hospitalist: a review. J Hosp Med 2012;7:489-96.

[9] Akerstedt T, Fredlund P, Gillberg M, et al. A prospective study of fatal occupational accidents - relationship to sleeping difficulties and occupationa factors. J Sleep Res 2002;11:69-71.

[10] Burgess HJ, Fogg LF. Individual differences in the amount and timing of salivary melatonin secretion. PLoS One 2008;3:e3055.

[11] Kudielka BM, Federenko IS, Hellhammer DH, et al. Morningness and eveningness: the free cortisol rise after awakening in "early birds" and "night owls". Biol Psychol 2006;72:141-6.

[12] Archer SN, Viola AU, Kyriakopoulou V, et al. Inter-individual differences in habitual sleep timing and entrained phase of endogenous circadian rhythms of BMAL1, PER2 and PER3 mRNA in human leukocytes. Sleep 2008;31: 608-17.

[13] Roenneberg T, Kuehnle T, Juda M, et al. Epidemiology of the human circadian clock. Sleep Med Rev 2007;11:429-38.

[14] Shirayama M, Shirayama Y, Iida H, et al. The psychological aspects of patients with delayed sleep phase syndrome (DSPS). Sleep Med 2003;4:427-33.

[15] Zhu L, Zee PC. Circadian rhythm sleep disorders. Neurol Clin 2012;30: 1167-91.

[16] Mongrain V, Carrier J, Dumont M. Circadian and homeostatic sleep regulation in morningness-eveningness. J Sleep Res 2006;15:162-6.

[17] Merikanto I, Lahti T, Kronholm E, et al. Evening types are prone to depression. Chronobiol Int 2013;30:719-25.

[18] Giannotti F, Cortesi F, Sebastiani T, et al. Circadian preference, sleep and daytime behaviour in adolescence. J Sleep Res 2002;11:191-9.

[19] Facer-Childs ER, Boiling S, Balanos GM. The effects of time of day and chronotype on cognitive and physical performance in healthy volunteers. Sports Med - Open 2018;4:47.

[20] Roenneberg T, Merrow M. Entrainment of the human circadian clock. Cold Spring Harbor Symp 2007;72:293-9.

[21] Khalsa SB, Jewett ME, Cajochen C, et al. A phase response curve to single bright light pulses in human subjects. J Physiol 2003;549:945-52.

[22] St Hilaire MA, Gooley JJ, Khalsa SB, et al. Human phase response curve to a $1 \mathrm{~h}$ pulse of bright white light. J Physiol 2012;590:3035-45.

[23] Crowley SJ, Eastman CI. Phase advancing human circadian rhythms with morning bright light, afternoon melatonin, and gradually shifted sleep: can we reduce morning bright-light duration? Sleep Med 2015;16:288-97.

[24] Kelly TL, Kripke DF, Hayduk R, et al. Bright light and LEET effects on circadian rhythms, sleep and cognitive performance. Stress Med 1997;13:251-8.

[25] Zeitzer JM, Fisicaro RA, Ruby NF, et al. Millisecond flashes of light phase delay the human circadian clock during sleep. J Biol Rhythm 2014;29:370-6.

[26] Mistlberger RE, Skene DJ. Nonphotic entrainment in humans? J Biol Rhythm 2005;20:339-52.

[27] Wehr TA, Wirz-Justice A, Goodwin FK, et al. Phase advance of the circadian sleep-wake cycle as an antidepressant. Science 1979;206:710-3.

[28] Miyazaki T, Hashimoto S, Masubuchi S, et al. Phase-advance shifts of human circadian pacemaker are accelerated by daytime physical exercise. Am Physiol Regul Integr Comp Physiol 2001:281:R197-205.

[29] Wehrens SMT, Christou S, Isherwood C, et al. Meal timing regulates the human circadian system. Curr Biol 2017;27:1768-17675 e3.

[30] Damiola F, Le Minh N, Preitner N, et al. Restricted feeding uncouples circadian oscillators in peripheral tissues from the central pacemaker in the suprachiasmatic nucleus. Genes Dev 2000;14:2950-61.

[31] Eastman CI, Hoese EK, Youngstedt SD, et al. Phase-shifting human circadianrhythms with exercise during the night-shift. Physiol Behav 1995;58: 1287-91.

[32] Buxton OM, Lee CW, L'Hermite-Balériaux M, et al. Exercise elicits phase shifts and acute alterations of melatonin that vary with circadian phase. Am Physiol Regul Integr Comp Physiol 2003;284:R714-24.

[33] Youngstedt SD, Elliott JA, Kripke DF. Human circadian phase-response curves for exercise. J Physiol 2019;597:2253-68. https://doi.org/10.1113/ JP276943.

[34] Joyce K, Pabayo R, Critchley J, et al. Flexible working conditions and their effects on employee health and wellbeing. Cochrane Database Syst Rev $2009 ; 2$.

[35] Lo JC, Lee SM, Lee XK, et al. Sustained benefits of delaying school start time on adolescent sleep and well-being. Sleep 2018;41.
[36] Paul MA, Gray GW, Lieberman HR, et al. Phase advance with separate and combined melatonin and light treatment. Psychopharmacology 2011;214: $515-23$.

[37] Petit E, Mougin F, Bourdin H, et al. Impact of 5-h phase advance on sleep architecture and physical performance in athletes. Appl Physiol Nutr Metabol - Physiologie appliquee, nutrition et metabolisme 2014;39:1230-6.

[38] Roenneberg T, Wirz-Justice A, Merrow M. Life between clocks: daily temporal patterns of human chronotypes. J Biol Rhythm 2003;18:80-90.

[39] Moreno C, Vasconcelos S, Marqueze E, et al. Sleep patterns in Amazon rubber tappers with and without electric light at home. Sci Rep-Uk 2015;5: 14074.

[40] Johns MW. A new method for measuring daytime sleepiness: the Epworth sleepiness scale. Sleep 1991;14:540-5.

[41] Buysse DJ, Reynolds 3rd CF, Monk TH, et al. The Pittsburgh Sleep Quality Index: a new instrument for psychiatric practice and research. Psychiatr Res 1989;28:193-213.

[42] McNair DM, LMDLF. Manual for the profile of mood states. San Diego, CA: Educational and Industrial Testing Service; 1971. p. 27.

[43] Lovibond PF, Lovibond SH. The structure of negative emotional States comparison of the depression anxiety stress scales (Dass) with the beck depression and anxiety inventories. Behav Res Ther 1995;33:335-43.

[44] Åkerstedt T, Gillberg M. Subjective and objective sleepiness in the active individual. Int J Neurosci 1990;52:29-37.

[45] Loh S, Lamond N, Dorrian J, et al. The validity of psychomotor vigilance tasks of less than 10-minute duration. Behav Res Methods Instrum Comput 2004;36:339-46.

[46] Bohannon RW. Dynamometer measurements of hand-grip strength predict multiple outcomes. Percept Mot Skills 2001;93:323-8.

[47] Marcora SM. Do we really need a central governor to explain brain regulation of exercise performance? Eur J Appl Physiol 2008;104:929-31.

[48] Facer-Childs E, Brandstaetter R. Circadian phenotype composition is a major predictor of diurnal physical performance in teams. Front Neurol 2015 Oct $1 ; 6: 208$.

[49] Rosenthal NE, Joseph-Vanderpool JR, Levendosky AA, et al. Phase-shifting effects of bright morning light as treatment for delayed sleep phase syndrome. Sleep 1990;13:354-61.

[50] Rosenthal NE, Sack DA, Gillin JC, et al. Seasonal affective disorder: a description of the syndrome and preliminary findings with light therapy. Arch Gen Psychiatr 1984;41:72-80.

[51] Chang A-M, Aeschbach D, Duffy JF, et al. Evening use of light-emitting eReaders negatively affects sleep, circadian timing, and next-morning alertness. Proc Natl Acad Sci Unit States Am 2015;112:1232-7.

[52] Santhi N, Thorne HC, van der Veen DR, et al. The spectral composition of evening light and individual differences in the suppression of melatonin and delay of sleep in humans. J Pineal Res 2012;53:47-59.

[53] Krauchi K, Cajochen C, Werth E, et al. Alteration of internal circadian phase relationships after morning versus evening carbohydrate-rich meals in humans. J Biol Rhythm 2002;17:364-76.

[54] Alvaro PK, Roberts RM, Harris JK. The independent relationships between insomnia, depression, subtypes of anxiety, and chronotype during adolescence. Sleep Med 2014;15:934-41.

[55] Levandovski R, Dantas G, Fernandes LC, et al. Depression scores associate with chronotype and social jetlag in a rural population. Chronobiol Int 2011;28: $771-8$.

[56] Krystal AD. Psychiatric disorders and sleep. Neurol Clin 2012:30:1389-413.

[57] Dinges DF, Pack F, Williams K, et al. Cumulative sleepiness, mood disturbance, and psychomotor vigilance performance decrements during a week of sleep restricted to 4-5 hours per night. Sleep 1997;20:267-77.

[58] Dinges DF. An overview of sleepiness and accidents. J Sleep Res 1995:4:4-14.

[59] Connor J, Whitlock G, Norton R, et al. The role of driver sleepiness in car crashes: a systematic review of epidemiological studies. Accid Anal Prev 2001;33:31-41.

[60] Chong MS, Ayalon L, Marler M, et al. Continuous positive airway pressure reduces subjective daytime sleepiness in patients with mild to moderate Alzheimer's disease with sleep disordered breathing. J Am Geriatr Soc 2006;54:777-81.

[61] Phipps-Nelson J, Redman JR, Dijk D-J, et al. Daytime exposure to bright light, as compared to dim light, decreases sleepiness and improves psychomotor vigilance performance. Sleep 2003;26:695-700.

[62] Rogers AE, Aldrich MS, Lin X. A comparison of three different sleep schedules for reducing daytime sleepiness in narcolepsy. Sleep 2001;24:385-91.

[63] Kaida K, Takahashi M, Akerstedt T, et al. Validation of the Karolinska sleepiness scale against performance and EEG variables. Clin Neurophysiol 2006;117:1574-81.

[64] Anderson C, Chang AM, Sullivan JP, et al. Assessment of drowsiness based on ocular parameters detected by infrared reflectance oculography. J Clin Sleep Med 2013;9:907-20.

[65] Borghini G, Astolfi L, Vecchiato G, et al. Measuring neurophysiological signals in aircraft pilots and car drivers for the assessment of mental workload, fatigue and drowsiness. Neurosci Biobehav Rev 2014;44:58-75.

[66] George C. Sleep. 5: driving and automobile crashes in patients with obstructive sleep apnoea/hypopnoea syndrome. Thorax 2004;59:804-7.

[67] Lenné MG, Triggs TJ, Redman JR. Time of day variations in driving performance. Accid Anal Prev 1997;29:431-7. 
[68] Facer-Childs E, Brandstaetter R. The impact of circadian phenotype and time since awakening on diurnal performance in athletes. Curr Biol 2015;25: $518-22$.

[69] Rae DE, Stephenson KJ, Roden LC. Factors to consider when assessing diurnal variation in sports performance: the influence of chronotype and habitual training time-of-day. Eur J Appl Physiol 2015;115:1339-49.

[70] Tamm AS, Lagerquist O, Ley AL, et al. Chronotype influences diurnal variations in the excitability of the human motor cortex and the ability to generate torque during a maximum voluntary contraction. J Biol Rhythm 2009;24:211-24.

[71] Banks S, Dinges DF. Behavioral and physiological consequences of sleep restriction. J Clin Sleep Med 2007;3:519-28.

[72] Lim J, Dinges DF. A meta-analysis of the impact of short-term sleep deprivation on cognitive variables. Psychol Bull 2010;136:375-89.
[73] Kline CE, Durstine JL, Davis JM, et al. Circadian rhythms of psychomotor vigilance, mood, and sleepiness in the ultra-short sleep/wake protocol. Chronobiol Int 2010;27:161-80.

[74] Basner M, Mollicone D, Dinges DF. Validity and sensitivity of a brief psychomotor vigilance test (PVT-B) to total and partial sleep deprivation. Acta Astronaut 2011;69:949-59.

[75] Wisløff U, Castagna C, Helgerud J, et al. Strong correlation of maximal squat strength with sprint performance and vertical jump height in elite soccer players. Br J Sports Med 2004;38:285-8.

[76] Bland JM, Altman DG. Comparisons against baseline within randomised groups are often used and can be highly misleading. Trials 2011;12:264. 